\title{
ENSINO DE LÍNGUA ESTRANGEIRA POR MEIO DE GÊNEROS TEXTUAIS: QUAL É A PERCEPÇÃO DOS PROFESSORES EM FORMAÇÃO?
}

\author{
Teaching Foreign Language Through Textual Genres: What Is Pre-service \\ Teachers`Perception?
}

\section{Valeska Gracioso CARLOS, UEL ${ }^{1}$ Marcella BORDINI, UEL ${ }^{2}$}

RESUMO: Este presente trabalho objetiva observar a percepção dos professores em formação de um curso de Letras de uma Universidade Pública do Centro Oriental Paranaense sobre estarem sendo preparados adequadamente para utilizar a abordagem pautada em Gêneros Textuais em sua prática de sala de aula. Como aporte teórico, nos pautamos em Cristovão (2002, 2007, 2010) Machado (2005, 2009), Abreu-Tardelli (2007, 2009) e Marcuschi (2008). A metodologia adotada é de base qualitativa e concerne na aplicação de um inventário de situações-problemas (MACEDO, 2002) a três turmas da terceira série de Língua Estrangeira (LE), sendo uma de francês, uma de inglês e uma de espanhol. Por meio das respostas obtidas, pudemos confirmar nossa hipótese de que esses professores em formação não estão preparados para a empregabilidade da abordagem pautada em Gêneros Textuais. Os resultados apontam que o gênero é somente usado como pretexto para o ensino de gramática, tradução, variação e não como ferramentas capazes de mediar ações socialmente elaboradas pelos sujeitos no momento da interação. Firma-se, desta forma, a necessidade de uma disciplina específica para prepará-los, de maneira mais eficiente, para a docência, uma vez que essa abordagem é a defendida pelos documentos oficiais para o ensino de Língua Materna e Estrangeira.

PALAVRAS-CHAVE: Gêneros Textuais; Ensino de Línguas Estrangeiras; Professor em Formação.

ABSTRACT: This article aims at observing the perception of the teachers in the Letras Course from a public University situated in the eastern-center of Paraná, about their preparation to use the textual genre approach in their classroom experiences. As our theoretical framework, we base ourselves in Cristovão (2002, 2007, 2010) Machado (2005, 2009), Abreu-Tardelli (2007, 2009) e Marcuschi (2008). The adopted methodology is based in qualitative and interpretative analysis and it concerns on the application of a problem solving inventory (MACEDO, 2002) in three Foreign Language 3rd year-classrooms: French, English and Spanish. Through the answers we have obtained, it was possible to confirm our hypothesis that these teachers are not being prepared for taking as a teaching methodology the approach based on textual

\footnotetext{
${ }^{1}$ Doutoranda em Estudos da Linguagem - UEL

${ }^{2}$ Mestranda em Estudos da Linguagem - UEL
} 
genres. The results show that the genre is only used objecting the study of grammar, translation and variation, and not as tool which is capable of mediating actions that are socially constructed by the subjects in the interaction moment. Likewise, there becomes necessary a specific discipline to prepare these teachers, in a more efficient way, so they can be able to teach, specially because the genre approach is presented in the official documents for vernacular and foreign language teaching.

KEY WORDS: Textual Genres; Foreign Language Teaching; Teacher in Educational Process

\section{INTRODUÇÃO}

Muitos são os estudos relativos ao ensino pautado em uma abordagem centrada nos Gêneros Textuais (Abreu-Tardelli, 2007; Cristovão, 2009; Machado, 2005; Marcuschi, 2008) no que diz respeito ao ensino de Língua Estrangeira (doravante LE), no entanto, a preocupação que nos concerne a esse trabalho é a de que os acadêmicos em formação não saem preparados para trabalhar com essa abordagem (RODRIGUES, 2008). Desta forma, faz-se necessária uma disciplina específica que contemple Gêneros Textuais, ensino e formação de professores, uma vez que esta abordagem é de fundamental importância na formação do futuro profissional de Letras.

A importância dessa discussão se dá à medida que a proposta dos documentos oficiais para o ensino de língua, materna ou estrangeira, tanto oral quanto escrita, está fundamentada na abordagem pautada em Gêneros.

Assumimos como base teórica para esse trabalho as concepções de linguagem e gênero textual centradas no processo de interação verbal defendidas por Bakthin (1953) e retomadas, posteriormente, por Bronckart (1999). Portanto, concebemos como Gêneros Textuais, os enunciados relativamente estáveis produzidos na interação verbal.

\section{A IMPORTÂNCIA DO ENSINO DE LÍNGUA ESTRANGEIRA SEGUNDO OS DOCUMENTOS OFICIAIS NACIONAIS}

\section{As Diretrizes Curriculares da Educação Básica do Estado do Paraná}

Por meio de um panorama histórico (LEFFA, 1999; MENEZES, 2009), é possível traçar alguns pontos importantes no ensino de Línguas Estrangeiras no Brasil, como a vinda dos jesuítas, a fim de catequizar os povos indígenas presentes no país, de 
1580 a 1640. O ministro Marquês de Pombal, em 1759, instituiu o sistema de ensino régio no país, e o Estado era responsável pela contratação de professores não-religiosos. Em 1809, D. João VI, assinou o decreto em 22 de junho, para criar as cadeiras de Inglês e Francês, e desta forma o ensino de línguas estrangeiras passou a ser valorizado. A abordagem gramática-tradução prevaleceu no ensino de línguas, desde que os jesuítas trouxeram consigo o Latim e o Grego com a finalidade de catequizar dos índios brasileiros.

Devido à propaganda brasileira na Europa, e as guerras, além da falta de emprego na maioria dos países europeus, muitos imigrantes vieram ao Brasil em busca de melhores condições de vida. No Estado do Paraná, em especial, houve a imigração de diversos povos, dentre eles, italianos, alemães, ucranianos, russos, poloneses e japoneses. Na busca por manter sua cultura e tradições, muitos colonos deram uma grande importância ao ensino, e se organizaram para construir e manter escolas para seus filhos.

Em 1917, o Governo Federal decidiu fechar as escolas construídas pelos imigrantes, a fim de manter uma cultura nacionalista, e em 1918 criou as escolas primárias subvencionadas com recursos federais sob a responsabilidade dos Estados. $\mathrm{O}$ movimento nacionalista se intensificou a partir do golpe de Estado, em 1937.

Em 1931, a Reforma intitulada Francisco Campos, em homenagem ao Ministro da Educação, atribuía à escola secundária a responsabilidade pela formação geral e preparação para o ensino superior dos estudantes. Por meio desta Reforma, foi estabelecido no país um novo método de ensino de LE: o método direto, o qual não mais entendia a língua como apenas um sistema de códigos, e sinais (por meio da gramática), mas como um meio de comunicação, impulsionando o ensino das habilidades orais da língua. Assim, passou-se a dar preferência ao professor nato, uma vez que se valorizava ainda mais a comunicação na língua alvo. Anteriormente o professor não precisava necessariamente dominar oralmente a língua ensinada.

Em 1939, durante a segunda guerra mundial, o Brasil se posicionou contra a Alemanha, e buscou ao máximo homogeneizar os brasileiros de sua língua materna- o português. Algumas minorias étnicas foram perseguidas dentro do país, uma vez que a presença de estrangeiros não era benéfica para a situação nacional da época, pois representavam um risco à segurança nacional.

A Reforma de Capanema, em 1942, contribuiu para a solidificação dos ideais nacionalistas. O curso secundário foi organizado em dois níveis: o ginasial em 4 anos e 
o colegial em 3 anos, e as línguas estrangeiras privilegiadas no nível ginasial, eram o Francês em primeiro plano, seguido do Inglês e o alemão, que poderia ser substituído pelo espanhol. O Latim permaneceu como língua clássica.

O currículo foi seguido pela recomendação do uso do Método Direto, apesar de que o ensino não deveria ter apenas fins instrumentais, mas sim, fins educativos. A responsabilidade pelos rumos educacionais passou a ser centralizada no Ministério da Educação e Saúde (MEC). O Espanhol passou a ser permitido oficialmente para compor o currículo do curso secundário, uma vez que não representava ameaça alguma para o Brasil, pois a quantidade de imigrantes vindos da Espanha era restrita. Assim, o ensino de Espanhol passou a ser valorizado, perante o ensino de outras línguas, como é o caso do alemão e do japonês, por exemplo. Mesmo com a valorização do espanhol no Brasil, o inglês e o francês se destacaram: o primeiro obteve uma posição de destaque, devido às transações econômicas, enquanto que o segundo possuía uma forte relação ao arsenal cultural que trazia consigo.

O ensino de inglês começou a se intensificar no Brasil em 1940, quando a nação estava em dívida com os EUA, e por isso havia a necessidade de se aprender inglês. Em 1950, o sistema educacional brasileiro se viu cada vez mais destinado a preparar os indivíduos, para o mundo do trabalho; o ensino de humanidades foi substituído por um currículo cada vez mais técnico e com isso veio a redução da carga horária para o ensino de línguas estrangeiras no país.

As LDB 4.204, de 1961, criou os Conselhos Estaduais de Educação e, cabia a eles, decidir sobre a inclusão ou não da LE no currículo. A mesma lei determinou a retirada da obrigatoriedade da LE no EM, e instituiu o ensino profissionalizante, compulsório, em substituição aos cursos Clássicos e Científicos.

Em 1942, houve a criação dos métodos áudio-visual (diálogos contextualizados) e audio-oral (repetição; abordagem formal dos fatos linguísticos), surgido nos EUA, onde era necessário formar pessoas rapidamente que falassem outras línguas.

A base estruturalista, na qual a língua é uma estrutura que faz intermediação entre o indivíduo e o mundo (elemento de ligação entre os dois), influenciou o ensino de LE e, em 1970, houve o estudo sobre a abordagem cognitiva e construtivista de Piaget, um dos maiores pensadores do século XX, que considerava a língua como interação entre o organismo e o ambiente. 
Além de Piaget, Vygotsky (1896-1934) foi bastante estudado no campo da aquisição da linguagem: esta é primeiramente externa ao indivíduo, para ser posteriormente internalizada por ele.

Segundo a Lei 5692/71, o governo militar proibiu o ensino de LE, a fim de que não houvesse uma dominação ideológica de outras sociedades e do colonialismo cultural do país. O Ensino de LE era privilégio da elite, e não das classes menos favorecidas.

Em 1976, o ensino de LE volta a vigorar no país e o inglês passa a ser ensinado apenas como um recurso instrumental. Algum tempo depois, foi criado o centro de Língua Estrangeiras Modernas (doravante LEM) em 1982, no Colégio Estadual do Paraná, que passou a oferecer aulas de inglês, espanhol, francês e alemão no contraturno da escola. Na mesma época, na UFPR, também foram incluídos outros idiomas no vestibular, como o italiano, o alemão e o espanhol, como uma valorização das LEMs. Devido a isso, houve uma grande demanda de professores para atuar no ensino dessas línguas.

Em 1986, foi criado pela Secretaria de Estado da Educação, o CELEM, Centro de Línguas Estrangeiras Modernas, como forma de valorizar o plurilinguismo e a diversidade étnica que marcou e ainda marca a história paranaense. A abordagem comunicativa foi tomada como base para o ensino, a qual foi espelhada no método europeu em meados dos anos 1970.

Alguns teóricos da área, como, Halliday (apud BRASIL, 2008) definia a língua como um sistema de escolhas de acordo com o contexto de uso. Em 1980, Canale e Swain, citados nas Diretrizes (2008, p.47) propuseram as quatro habilidades para o ensino de línguas: leitura, escrita, fala e audição. Posteriormente, Bachman (1990) apresentou o modelo de competência comunicativa e desempenho, no qual o uso da língua requer tanto o seu conhecimento, quanto a capacidade de implementação ou de seu uso. Assim, o professor passa a ter um papel de mediador, e o aluno é o sujeito de sua aprendizagem. A Abordagem comunicativa representava uma reação à visão estruturalista da língua, concentrando-se em aspectos semânticos e não no código linguístico, e logo passou a ser alvo de críticas por alguns intelectuais da área.

O surgimento das teorias da Análise do Discurso da Escola Francesa contribuiu para uma nova orientação de ensino/aprendizagem no Brasil, cujo foco centrava-se no texto e não mais na gramática. 
Em 1996, a LDB nacional, determinou a obrigatoriedade de pelo menos uma LE no currículo, no ensino fundamental, a partir da quinta série, e a escolha do idioma foi atribuída à comunidade escolar. Para o Ensino Médio, uma LEM seria obrigatória, e deveria ser ofertada outra em caráter optativo.

O MEC publicou em 1998, os PCN - Parâmetros Curriculares Nacionais - para o Ensino Fundamental, documento que defende a concepção de língua como prática social. Além disso, a prática de leitura foi afirmada como essencial em detrimento das outras práticas, como oralidade e escrita, com a justificativa de que no contexto brasileiro há poucas oportunidades de uso efetivo da oralidade pelos alunos, particularmente aqueles da rede pública de ensino. Em 1999 o MEC publicou os PCN para o EM (Ensino Médio), cuja ênfase está na comunicação oral e escrita.

Para destacar o Brasil no MERCOSUL, foi criada em 2005, a Lei $\mathrm{n}^{\circ} 11.161$ (05/08/2005) que tornou obrigatória o ensino de espanhol nos estabelecimentos de Ensino Médio. Esta lei teve como fundamento de sua criação, os interesses políticos e econômicos, para melhorar as relações comerciais entre o Brasil e os países de língua espanhola. Apesar da oferta desta disciplina no Ensino Médio ser obrigatória, sua matrícula é facultativa pelo aluno. Para suprir esta demanda, foi lançado um concurso público para compor o quadro do magistério, para professores de espanhol, para suprir a demanda prevista pela lei.

Buscam-se fundamentos teórico-metodológicos para subsidiar o ensino de LEM no processo de escolarização, pois a Abordagem Comunicativa não levou em consideração a comunicação intercultural, como ressalva Gimenez (apud BRASIL, 2008).

De acordo com as Diretrizes Curriculares do Estado do Paraná (2008, p. 51): “... depreende-se que tanto a opção teórico-metodológica quanto o idioma a ser ensinado na escola não são neutros, mas sim, profundamente marcados por questões políticoeconômicas e ideológicas".

Logo a seguir, temos alguns dos fundamentos teórico-metodológicos que referenciam estas Diretrizes e os princípios que orientam a escolha pelo plurilinguismo como política educacional, como uma das possibilidades de valorização e respeito à diversidade cultural, pois permite às comunidades escolares a definição da LE a ser ensinada (p.52): 
- o atendimento às necessidades da sociedade contemporânea brasileira e a garantia da equidade no tratamento da disciplina de LE Moderna em relação às demais obrigatórias do currículo;

- o resgate da função social e educacional do ensino de LE no currículo da Educação Básica;

- o respeito à diversidade (cultural, identitária, linguística), pautado no ensino de línguas que não priorize a manutenção da hegemonia cultural.

A pedagogia crítica é o referencial teórico que sustenta o documento de Diretrizes Curriculares. Esta abordagem foi estudada por autores seminais, como Freire (1970), Giroux (1997) e Saviani (2005). Saviani (2005, p.7) argumenta que: “o saber que diretamente interessa à educação é aquele que emerge como resultado do processo de aprendizagem, como resultado do trabalho educativo". Por meio da pedagogia crítica, entende-se que o aluno não deve apenas assimilar o saber como resultado, e sim como ferramenta de transformação em seu meio social. A relação entre língua e pedagogia crítica é essencial no atual contexto globalizado. Propõe-se que a aula de LE constitua um espaço no qual o aluno possa compreender a diversidade linguística e cultural. Espera-se que o aluno compreenda que os significados são sociais e historicamente construídos, e, portanto, passíveis de transformação na prática social.

A proposta das Diretrizes se concentra na corrente sociológica e nas teorias do Círculo de Bakhtin, que toma a língua como discurso. Assim, busca-se estabelecer os objetivos de ensino de uma LE, bem como resgatar a função social, educacional desta disciplina na Educação Básica.

Segundo Bakhtin (1988), todo discurso se constrói na interação com o outro, portanto é nessa relação com o outro que nos constituímos socialmente. Deste modo, por meio de uma LE, passamos a conhecer outras realidades, outros significados, os quais são acrescentados ao que até então conhecemos. Como consequência, tornandonos ainda mais críticos com relação aos saberes por nós já adquiridos. No ensino de LE, a língua, objeto de estudo dessa disciplina, contempla as relações entre cultura, sujeito e identidade. As aulas de LE se configuram como espaços de interações entre professores e alunos e pelas representações e visões de mundo que se revelam no dia-a-dia.

Espera-se que a aula de LE também seja um espaço para a reflexão, a fim de transformar os alunos em seres pensantes, críticos e agentes do mundo em que vivem. Outro excerto interessante retirado das Diretrizes, no que concerne a LE: (BRASIL, 2008, p. 56): 
[...] Espera-se que o aluno:

- use a língua em situações de comunicação oral e escrita;

- vivencie, na aula de Língua Estrangeira, formas de participação que lhe possibilitem estabelecer relações entre ações individuais e coletivas;

- compreenda que os significados são sociais e historicamente construídos e, portanto, passíveis de transformação na prática social;

- tenha maior consciência sobre o papel das línguas na sociedade;

- reconheça e compreenda a diversidade linguística e cultural, bem como seus benefícios para o desenvolvimento cultural do país. (BRASIL, 2008, p. 56)

Para tanto, é preciso fornecer os subsídios necessários fornecer ao aluno, para que ele se envolva em sua comunidade local, de forma íntegra e ativa. A parte que trata da comunicação oral e escrita faz-se essencial, na medida em que o aluno deve entender o quão importante é o ato de se comunicar, de fazer parte do meio social, e ter o poder de transformação. A LE também possibilita uma entrada em uma nova cultura, uma nova visão de mundo pelos alunos.

Os professores devem sempre buscar incluir socialmente os alunos, por meio da Educação e do transpassar de um novo conhecimento, porém ter em mente que o aluno não é um copo vazio, no qual temos o direito de despejar todo o conteúdo que queremos, a fim de que ele saia "fabricado" da forma como desejamos. Afinal, todos os alunos são seres humanos e possuem uma história de vida e uma cultura, as quais devem ser respeitadas pela escola. Além disso, a LE permite uma nova percepção de mundo pelos alunos.

Como a base das Diretrizes Curriculares é a interação ativa por meio do discurso, os alunos devem passar por um processo de aprendizagem focado na leitura de textos para entender o mundo, e assim se tornarem cidadãos críticos perante tudo o que foi lido, discutido, analisado. A construção da linguagem se dá de maneira social, e isso significa dizer que os alunos devem se tornar seres autônomos na construção dos significados dos textos, uma vez que já terão passado por um processo de socialização (p. 58):

O trabalho com a Língua Estrangeira Moderna fundamenta-se na diversidade de gêneros textuais e busca alargar a compreensão dos diversos usos da linguagem, bem como a ativação de procedimentos interpretativos alternativos no processo de construção de significados possíveis pelo leitor. (grifo nosso). 
As Diretrizes propõem um trabalho com leitura crítica na (re)construção de novos significados, uma vez que o Conteúdo Estruturante da LE Moderna se pauta no Discurso como prática social. Como há uma infinidade de gêneros a serem trabalhados, o professor deve refletir sobre os critérios ao lançar os conteúdos da disciplina de LE, verificando sempre a qualidade dos textos, os quais devem instigar o aluno à reflexão e à discussão em sala de aula. Os encaminhamentos metodológicos para a Educação Básica consistem no Conteúdo Estruturante, o qual é representado pelo Discurso como prática social, $e$ desta forma o trabalho com o aluno deve focar em questões linguísticas, sociopragmáticas, culturais e discursivas, bem como as práticas do uso da língua: leitura, oralidade e escrita. Os textos a serem trabalhados são tanto de natureza verbal quanto não-verbal, uma vez que ambos incitam o pensamento reflexivo do aluno.

Propõe-se que, nas aulas de Língua Estrangeira Moderna, o professor aborde os vários gêneros textuais, em atividades diversificadas, analisando a função do gênero estudado, sua composição, a distribuição de informações, o grau de informação presente ali, a intertextualidade, os recursos coesivos, a coerência e, somente depois de tudo isso, a gramática em si. (BRASIL, 2008, p.63)

A prioridade é trabalhar com os textos, sem abandonar o conteúdo gramatical. É necessário contextualizar os gêneros textuais a serem trabalhados, enfatizando elementos como locutor/interlocutor do texto em questão, a finalidade da escrita, o público-alvo do texto, enfim aspectos relevantes que incitem a criticidade do aluno.

Como nem todos os alunos dispõem de um léxico suficiente para se comunicar em língua inglesa, as Diretrizes propõem que as discussões acerca dos textos podem ocorrer em Língua Materna, as quais podem servir como subsídio para a produção textual em LE.

Para que uma leitura em LE seja alcançada, é necessário subsidiá-lo com alguns elementos, como os linguísticos, sociopragmáticos, culturais e discursivos.

Faz-se necessária a abordagem não apenas do livro didático, que representa uma das ferramentas de trabalho do professor, mas sim o uso de outros materiais em sala de aula (CD, DVD, entre outros), para tornar o ambiente mais dinâmico e didático, ou seja, que levem o aluno a se interessar pelo aprendizado de LE. O aprendizado ocorre de inúmeras formas, e na atualidade, nós professores, temos em nossas mãos uma infinita gama de materiais que poderiam ser utilizados para o ensino, contudo não o são. As políticas governamentais deveriam ser voltadas às reais necessidades tanto da escola, 
quanto do professor, em tempos atuais; devido ao crescente avanço da tecnologia, tornase fundamental que recursos tecnológicos recentes sejam implantados nas escolas, a fim de que os professores possam concluir o seu trabalho com êxito, como é sugerido pelas Diretrizes Curriculares do Estado do Paraná.

Outro aspecto importante a ser discutido é a forma de avaliação adotada por nossas escolas brasileiras, certamente seguindo regras governamentais. A avaliação é vista como uma forma de julgar o conhecimento do aluno, de 0-10, de 0-100, ou de AE, o que não representa em sua escala real o conhecimento plenamente adquirido pelo aluno. A avaliação se constitui como uma ferramenta de medição da apreensão de conteúdos, a qual julga se o aluno está apto ou não para avançar mais um nível. É uma ferramenta necessária por certo viés, mas por outro é extremamente inútil, uma vez que o fato do aluno ter atingido a nota máxima em alguma atividade proposta pelo professor, não significa que está apto a encarar os milhares de desafios mundo afora, muito menos que é um leitor ativo. A avaliação (LUCKESI, 1995; ROMÃO, 1998; RAMOS, 2001; FIDALGO, 2002) deveria alterar o seu sentido, à medida que ao mesmo tempo em que contribui para o avanço do aluno na vida escolar, faz com que este esteja apto para a vida, e utilize dos conhecimentos adquiridos na escola em todas as atividades que se propuser a realizar no futuro.

\section{OS GÊNEROS TEXTUAIS E O ENSINO DE LÍNGUAS ESTRANGEIRAS}

Segundo Marcuschi, (2008, p. 150), "cada gênero textual tem um propósito bastante claro que o determina e lhe dá uma esfera de circulação". A linguagem, segundo o autor, está em função das atividades culturais e sociais, ou seja, a linguagem permeia a convívio social, e é por meio deste que ela se desenvolve.

Existem algumas perspectivas teóricas internacionais a respeito dos gêneros, como a perspectiva sócio-histórica e dialógica, a comunicativa, a sistêmico-funcional, a sociorretórica de caráter etnográfico voltada para o ensino de segunda língua, a interacionista e sociodiscursiva de caráter psicolinguístico, a análise crítica e a sociorretórica/sócio-histórica e cultural. Neste trabalho, embasamo-nos na perspectiva dialógica de Bakhtin (1953), uma vez que as Diretrizes Curriculares da Educação Básica do Estado do Paraná se pautam no Discurso como Prática Social. 
Marcuschi (2008) defende a ideia de que é impossível não se comunicar verbalmente por algum gênero ou texto. Os gêneros textuais representam muito mais que tipologias textuais (nos quais estão inseridos a narração, a descrição, a argumentação); os gêneros textuais estão presentes em nosso cotidiano, em nossa esfera comunicativa, em nosso meio social, na forma de textos orais ou escritos, e é por meio dos gêneros textuais que nos socializamos com o meio no qual estamos inseridos.

O Discurso como Prática Social, pautado nas Diretrizes, envolve a questão da interação dos indivíduos, no meio social para a produção da linguagem em determinado contexto de atuação. Bakhtin (1986) em sua obra Marxismo e Filosofia da Linguagem discute sobre o aspecto interação, a qual se faz necessária para que a comunicação verbal concreta exista. Além disso, a interação pressupõe o social e suas relações com os grupos sociais e é ela que produz a palavra, e é essencial para que haja a interligação de dois elementos, dois indivíduos, no processo de comunicação por meio de gêneros textuais. Se partirmos do pressuposto de Bakhtin de que os gêneros são formas relativamente estáveis de enunciados que possibilitam a interação, a comunicação e a ação no mundo, devemos considerar o sujeito como agente modificador do processo socio-histórico do gênero.

Marcuschi (2008, p. 159), faz a seguinte definição: “...os gêneros não são entidades formais, mas sim entidades comunicativas em que predominam os aspectos relativos a funções, propósitos, ações e conteúdos”. Assim é possível afirmar que numa aula de LE, se o aluno for exposto a uma série de conhecimentos que envolvam os gêneros textuais, ele compreenderá o sentido que possui a leitura de um determinado texto, bem como sua função no meio social, pois quando escrevemos, o fazemos por um propósito maior, no intuito de enviar uma mensagem a um determinado público-leitor, e tentar persuadi-lo de nossas ideias, ou simplesmente transpassar um determinado tipo de conhecimento. A comunicação é um fator poderoso no ensino por meio de gêneros textuais, pois inclui o meio social, a interação humana, e não somente o ensino de língua como mera estrutura fixa e estável.

Os gêneros textuais também abarcam a questão da cultura, tanto defendida pelas Diretrizes, quanto pelos PCN e OCEM. A cultura está permeada pela linguagem, pela comunicação verbal dos povos, e ensinar língua não significa pautar-se apenas e tão somente na sua estrutura e função, mas sim na sua inserção no mundo, nas sociedades cada vez mais heterogêneas e possuidoras de características peculiares, as quais devem ser respeitadas, e valorizadas por todos nós, no que concerne o ensino de língua. 
Os Gêneros Textuais são construções sociais, logo adquirem seu sentido próprio socialmente, por meio da interação dos indivíduos na comunicação. A comunicação mediada pelo computador (CMC), por exemplo, pode ser representada por vários gêneros textuais bastante discutidos recentemente, e podem ser apresentados aos alunos, no ensino de LE, a fim de torná-los conscientes de como a linguagem se modifica de acordo com o contexto de sua atuação. Estes gêneros textuais criados a partir do discurso eletrônico se tornaram relevantes, na medida em que hoje representam um tipo de gênero em franco desenvolvimento.

Assim, o ensino por meio de gêneros textuais, não apenas pautado na parte sistêmica da língua, como a gramática, a norma padrão, enfim outros aspectos linguísticos estruturais, consiste num ensino mais amplo e mais crítico, uma vez que utiliza dos textos que circulam na esfera do aluno. Conforme Abreu-Tardelli (2007, s/p), “ensinar gênero não é ensinar a se comunicar, mas também e principalmente, formar sujeitos agentes do mundo e no mundo, agentes que irão transformar o mundo e que também serão transformados por ele".

Se partirmos dos pressupostos teóricos do interacionismo sociodiscursivo (ISD), o qual defende que a linguagem é predominantemente social e decorrente das interações, e que o aprendizado se dá na interação com o outro, podemos conceber a linguagem como ferramenta ou instrumento de aprendizagem. Desta forma, é possível pautar o ensino de LE em gêneros se adotarmos o conceito de gêneros como instrumentos $^{3}$ de ensino, defendido por Dolz e Schneuwly (1996; 1998 apud ABREUTARDELLI, 2007). De acordo com os autores, uma das funções do gênero é auxiliar o desenvolvimento das diferentes habilidades de linguagem que mobilizamos na interação seja de forma oral ou escrita. Assim, o trabalho com o gênero em sala de aula deve proporcionar ao aluno a oportunidade de interagir com a linguagem e de desenvolver as capacidades de linguagem (DOLZ \& SCHNEWLY, 1996; 1998).

Segundo Szundy e Cristovão (2008), é preciso formar professores capazes de refletir sobre suas próprias ações, para que haja possíveis transformações em suas práticas pedagógicas; o professor deve ser, além de ministrante de suas aulas, um bom pesquisador de sua própria prática. As práticas em sala de aula representam uma oportunidade que o professor possui de repensar a sua prática, e a abordagem que utiliza na elaboração de suas aulas. O professor precisa analisar o seu contexto de atuação -

\footnotetext{
${ }^{3}$ Alguns autores preferem a palavra "ferramenta" para "instrumentos".
} 
sala de aula - uma vez que os contextos variam sempre; assim, o trabalho se tornará mais eficiente ao conhecer o contexto de ensino, com a possibilidade de elaboração de um projeto pedagógico, além de unidades de ensino e atividades.

Ao analisar o contexto de ensino, o professor é capaz de determinar o gênero textual a ser trabalhado, pois domina aquele ambiente de atuação, os seus alunos, e a sua produção de linguagem que será exigida durante uma aula de LE, por exemplo.

\section{METODOLOGIA}

A pesquisa proposta é de cunho qualitativo, pois terá como fonte direta de coleta de dados o ambiente natural, sendo o pesquisador o seu principal instrumento. Ademais, os dados coletados serão de natureza predominantemente descritiva, os quais incluem transcrições de entrevistas e depoimentos (LÜDKE E ANDRÉ, 1996).

Para a realização desse estudo optamos pela aplicação de um inventário de situação-problema ${ }^{4}$ a três turmas da terceira série de LE de uma Universidade do estado do Paraná, sendo uma de francês, uma de inglês e uma de espanhol. O inventário contendo cinco questões foi preparado previamente de acordo com as teorias de Meirieu (1998), Perrenoud (2000) e Macedo (2002) e aplicado em sala de aula com a ajuda do professor de LE das turmas em questão.

A opção em utilizar um inventário de situação-problema surgiu da necessidade de induzir aos acadêmicos, professores em formação, a refletir e lidar sobre questões referentes ao como ensinar a LE. De acordo com Macedo (2002) uma característica da situação problema é desafiar o aluno para resolução de uma questão complexa que implica em mobilizar recursos, tomar decisões e ativar esquemas. "A situação-problema pede um posicionamento, pede um arriscar-se, coordenar fatores em um contexto delimitado, com limitações que nos desafiam a superar obstáculos, em pensar em um outro plano ou nível" (Macedo, 2002, p. 115).

O inventário continha uma introdução explanatória sobre como responder às perguntas e tratava de questões referentes aos conhecimentos teóricos e à prática

\footnotetext{
${ }^{4}$ Philippe Meirieu em seu livro “Aprender... Sim, mas como?” define situação-problema como "situação didática na qual se propõe ao sujeito uma tarefa que ele não pode realizar sem efetuar uma aprendizagem precisa. Esta aprendizagem, que constitui o principal objetivo da situação-problema, se dá ao vencer o obstáculo na realização da tarefa. Assim a produção impõe a aquisição, uma e outra devendo ser o objeto de avaliações distintas. Como toda situação didática, a situação-problema deve ser construída apoiando-se em uma tripla avaliação diagnóstica (motivações, competências e capacidades)” (p. 192).
} 
pedagógica desses professores em formação. Vale ressaltar que no terceiro ano desse curso de Letras, os acadêmicos entram em sala de aula pela primeira vez devido à disciplina de Estágio Supervisionado de Língua Portuguesa. Além disso, muitos alunos já se encontram em sala de aula ministrando, por vezes, aulas de LE. As questões do inventário em momento algum mencionavam a palavra "Gênero", no entanto exigiam um posicionamento e uma justificativa para a escolha de uma abordagem para o ensino de LE.

Como mencionado anteriormente, optamos pela participação de três turmas de terceiras séries que estudam LEs diferentes e, portanto, poderiam apresentar concepções também diferentes quanto à abordagem escolhida. Dos alunos de Língua Espanhola tivemos a participação de $100 \%$ do grupo, num total de 20 acadêmicos. Em Língua Francesa também tivemos $100 \%$ de participação, totalizando 9 acadêmicos. Já com relação aos alunos de Língua Inglesa, apenas 4 dos 17 acadêmicos responderam ao inventário. Desta forma, nosso corpus se constituiu de 33 inventários.

Para melhor compreensão dos dados chamaremos nossos participantes alunos do curso de Letras Português/Espanhol com a letra E, e usamos números de 1 a 20 para diferenciá-los. Para os alunos de Letras Português/Francês utilizamos a letra $\mathrm{F}$ e número de 1 a 9. Para os de Letras Português/ Inglês adotamos a letra I e números de 1 a 4. Desta forma, teremos para esse estudo:

Para a Língua Espanhola: E1, E2, E3, E4...... E20.

Para a Língua Francesa: F1, F2, F3, F4 ..... F9.

Para a Língua Inglesa: I1, I2, I3 e I4.

O inventário se encontra na íntegra, como apêndice, nesse artigo.

\section{DISCUSSÃO DOS DADOS}

Para facilitar a análise do corpus e a compreensão por parte dos leitores tratamos os dados de acordo com o tópico contido em cada questão de nosso inventário.

Questão 1 - Abordagem

Pudemos perceber por meio dos dados que os participantes de nossa pesquisa, em geral, não sabem o conceito de abordagem. Alguns misturam sua definição com 
métodos, outros acham que abordagem é o mesmo que tema gramatical ou assunto a ser tratado na aula. Muitos participantes sugeriram trabalhos embasados na interculturalidade, sobretudo com a LE.

Dos participantes da Língua Espanhola apenas dois deles trataram em suas respostas sobre abordagens, o participante E17 afirma que trabalharia usando a abordagem comunicativa sociointeracionista e o participante E15 escolheu a abordagem comunicativa para sua prática. No entanto, não conseguem justificar sua opção pela abordagem.

Entre os acadêmicos de francês, F7 afirma que prefere a abordagem audiovisual, "porque não tem como trabalhar somente a abordagem escrita, ou só a oral, ou só a auditiva". F5 expõe que prefere a abordagem sociointeracionista, "afinal é a que estamos aprendendo na universidade". F8 apenas menciona a abordagem comunicativa, sem ao menos se justificar.

Os alunos de língua inglesa parecem ter maior entendimento sobre a questão. I1 é a favor da abordagem sociointeracionista, a qual é defendida por Bronckart (1999), e seus sucessores como Machado (2005, 2009) e Cristóvão (2002, 2007, 2010), que em cada um de seus textos desenvolvem um pouco mais a ideia de interacionismo sociodiscursivo, sobretudo, com relação à educação e à formação de professores. I1 afirma que: "porque por meio dessa abordagem pode-se envolver o aluno na construção do conhecimento, fazendo com que se sinta realmente inserido nesse processo de ensino-aprendizagem". I2 também optou pela abordagem sociointeracionista "porque ela envolve o aluno, considera a educação como uma ação conjunta, não apenas do professor para o aluno. I3 afirma que "escolheria a abordagem baseada em gêneros textuais e nas denominadas sequências didáticas, já que é possível, a partir disso, se fazer um estudo mais sistematizado e significativo do gênero escolhido". I4 diz que "escolheria fazer uma abordagem do texto, seguindo uma sequência didática a respeito de um gênero textual específico, pois os alunos precisam aprender a produzir diversos gêneros textuais para estarem preparados para eventuais situações cotidianas que exijam esses conhecimentos."

Por meio da primeira questão pudemos perceber que apenas os alunos de Língua Inglesa apresentam um conhecimento mais sistemático do que venha a ser abordagem. Também foram os únicos que citaram a abordagem baseada em gêneros textuais. Conforme I3, a partir de gêneros textuais e sequências didáticas, é possível "se fazer um estudo mais sistematizado e significativo do gênero escolhido". Para I4 "eu escolheria 
fazer uma abordagem a partir do texto, seguindo uma sequência didática a respeito de um gênero textual específico, pois os alunos precisam aprender a produzir diversos gêneros textuais para estarem preparados para eventuais situações cotidianas que exijam esses conhecimentos".

\section{Questão 2 - Trabalho com conteúdo por meio da abordagem escolhida}

Entre os participantes de Língua Espanhola, podemos citar o participante E17, que apóia sua escolha da abordagem comunicativa por meio de interpretações de papéis (role-play). Dos alunos de Língua Francesa nenhum deu suporte à resposta anterior. Entre os acadêmicos de inglês, apenas dois trabalhariam com gêneros. I3 afirma que escolheria um gênero para fazer uma análise contextualizada. I4 afirma que se, por exemplo, fosse tratar do imperativo usaria o gênero receita ou manual de instruções.

De acordo com as respostas obtidas verificamos a dificuldade que os professores em formação apresentam quanto à transposição didática, pois mesmo os que apoiaram uma abordagem, não conseguiram aplicá-la em suas respostas, o que nos leva a crer que tampouco conseguiriam transpor a teoria em prática. A questão da abordagem é amplamente discutida nas DCE (2008), uma vez que o ensino de Línguas Estrangeiras no Brasil sempre esteve preocupado em escolher a melhor abordagem de ensino, a fim de englobar todas as habilidades, requeridas aos alunos, no momento de sua aprendizagem.

Assim, cabe a nós professores, repensar sobre o que este documento de extrema relevância nos propõe. Não se trata de escolher a abordagem comunicativa a fim de capacitar o aluno no falar da língua, e sim fazê-lo compreender que o ato de falar acompanha uma série de outros aspectos significativos no ensino de LE no país como um todo, como por exemplo, a diversidade cultural, a existência de milhares de variedades linguísticas presentes numa mesma língua. A importância do ensino de Línguas Estrangeiras no Brasil se dá principalmente em ampliar o horizonte dos alunos, e não simplesmente torná-los mecânicos robôs que repetem palavras e não sabem o sentido das mesmas porque estas são assim apresentadas dentro da sala de aula pelo professor.

Questão 3 - Gêneros virtuais de comunicação (MSN, Chat, Skype) 
Por meio dessa questão, pôde-se entender que em sua maioria, mesmo que os acadêmicos tenham consciência da importância desses gêneros virtuais, o gênero é somente usado como pretexto para ensino de gramática, tradução, variação entre língua escrita e oral ou padrão e coloquial. Em nenhum momento houve comentários em se tratar da importância do gênero e sua aplicabilidade. Conforme os acadêmicos, esse tipo de atividade desperta o interesse dos alunos, mas muitas vezes, a escola não está preparada com a tecnologia necessária. Baseado nisso, E3, E7 sugerem o trabalho com textos produzidos em redes sociais. E9, E12 e E17 mencionam a oportunidade em se comunicar em LE com um nativo ou com alunos de outras turmas e F7 menciona a importância da comunicação em tempo real. E6 e E11 ressaltam a importância em alertar os alunos quanto aos perigos da internet. E3 sugere a criação de um twitter para posts na LE. Alguns professores em formação, E5, E14 e I4 sugeriram a criação de blogs.

Para Abreu-Tardelli (2010), ao considerarmos MSN, Chat, Skype no contexto de sala de aula como ferramentas no contexto escolar podemos considerá-los como novos gêneros educacionais, o que para Bakhtin é uma característica própria do gênero que não é estático e está sujeito a modificações decorrentes das transformações da sociedade. Desta forma, esses gêneros virtuais estão se constituindo e se modificando, ao mesmo tempo em que constituem e modificam os sujeitos/agentes da situação.

Assim, podemos inferir que esses gêneros não são vistos, pelos professores em formação, como ferramentas capazes de mediar ações socialmente elaboradas pelos sujeitos no momento da interação. Acreditamos que uma das razões para tal ocorrência pode ser a falta de domínio do gênero pelos usuários. Por isso, ressaltamos a importância da necessidade em aprofundar os estudos dos gêneros virtuais como ferramentas de ensino, pois é nosso papel como educadores nos adaptarmos às transformações do mundo em que vivemos para que possam ser exploradas no contexto de sala de aula.

\section{Questão 4-Gênero HQ}

De acordo com as respostas, as HQs devem ser trabalhadas de maneira que os alunos possam criar suas próprias HQs ou traduzi-las para a língua alvo. Segundo F9, a escolha deve ser baseada na informação transmitida pela HQ, questões polêmicas como 
racismo, defesa do meio ambiente. Já a participante I3 afirma que as HQs são um gênero textual e, portanto, pode ser estudado como qualquer outro gênero.

Parece-nos que as HQs são, aqui também, usadas como pretexto para o ensino de gramática e tradução ou produção textual, sem que haja reflexão a cerca do gênero. Podemos citar como documentos oficiais as DCE (BRASIL, 2008), documento que defende a ideia de que a aula deve ser embasada no texto como um todo, e não apenas utilizá-lo como pretexto, a fim de traduzi-lo, ou ensinar a gramática presente nele. $\mathrm{O}$ texto, a HQ neste caso, deve ser muito bem selecionada pelo professor, pois o próprio documento preza a parte conteudística sobre qualquer assunto a ser transpassado aos alunos. O ensino tradicional é enfrentado pelas DCE, uma vez que pouco ou quase nada relevante é utilizar a aula de LE puramente como um espaço de tradução de palavras descontextualizadas, e que certamente não acrescentarão conhecimento palpável ao aluno, em suas maiores necessidades no que concerne a LE.

\section{Questão 5 - Avaliação}

É consenso para os participantes que a avaliação deve ser um processo diário não medido apenas pela prova escrita. De acordo com os participantes, além da prova escrita o professor deve preparar uma prova oral no caso da LE, e avaliar o aluno diariamente por meio de sua participação em aula e também pelo seu desenvolvimento durante o ano. F6 ressalta a importância de a avaliação abranger as quatro habilidades, leitura escrita, exercícios de compreensão auditiva e oral. E4 afirma que é importante que a avaliação seja elaborada a partir de textos e "não avaliar de conteúdos isolados, mas dentro de um contexto, dentro de possibilidades que permitam o aluno reflexão". Já segundo I3, "tomando como abordagem a sequência didática, poder-se-ia avaliar o processo de ensino-aprendizagem como um todo, isto é, desde o reconhecimento do gênero até a produção final."

Em suma, podemos afirmar que os acadêmicos participantes da pesquisa não têm uma noção clara do que venha ser abordagem, o que ficou comprovado com as respostas da segunda questão, pois estes não puderam sustentar suas escolhas ou mesmo justificá-las. No que tange os gêneros virtuais e o gênero $H Q$, percebemos mais um uso do gênero como pretexto para o ensino de leitura, escrita, gramática, sem que fossem mencionados os processos de reconhecimento, de criação e circulação dos gêneros mencionados, ou seja, não foram explorados os aspectos discursivos e linguísticos de 
forma contextualizada. Quanto à avaliação, os professores em formação são conscientes da importância de uma avaliação contínua, como parte de um processo, no entanto, apenas dois de 33 participantes vêem a sequência didática como uma alternativa a essa questão.

\section{CONSIDERAÇÕES FINAIS}

Após a análise dos documentos oficiais, de nossa revisão bibliográfica, e dos dados expostos na seção anterior, algumas considerações se fazem necessárias.

A análise dos inventários de situação-problema corroborou a nossa primeira hipótese, de que os professores em formação apresentam dificuldades com relação à empregabilidade no ensino de uma abordagem pautada em gêneros textuais. Desta forma, há de se repensar no curriculum dos cursos de Licenciatura em Letras com habilitação em Língua Materna ou Estrangeira, pois não estamos preparando nossos futuros professores para seguir as orientações sugeridas pelos documentos oficiais, sejam eles, PCN, OCEM ou DCE. $\quad$ O estudo dos gêneros textuais não é novo, no entanto, no que tange a sua aplicabilidade, ainda estamos longe de alcançarmos nossos objetivos em sala de aula. Além disso, podemos considerar que a abordagem em gêneros requer certo tempo de preparo e dedicação que, muitas vezes, falta ao profissional da área de Letras. Diferentemente da Universidade analisada, a Universidade Estadual de Londrina, por exemplo, conta com a presença de uma disciplina voltada ao estudo dos gêneros textuais, já na graduação, o que resulta em uma formação profissional mais direcionada às tendências atuais de ensino-aprendizagem.

Por meio dos dados obtidos, pudemos observar que os participantes apresentam dificuldades com o conceito de abordagem, o que dificulta sua transposição didática, pois mesmo os que apoiaram uma abordagem, não conseguiram aplicá-la em suas respostas. Ademais, para os participantes, o gênero é somente usado como pretexto para o ensino de gramática, tradução, variação e não como ferramentas capaz de mediar ações socialmente elaboradas pelos sujeitos no momento da interação. Assim, reafirmamos que existe uma grande necessidade da implantação de uma disciplina na grade dos alunos de graduação em Letras, que compreenda todos os aspectos a respeito dos gêneros textuais, uma vez que esse conhecimento se faz essencial na preparação de uma aula, e na formação do professor, pois ele será o mediador da interação entre seus alunos. 


\section{REFERÊNCIAS}

ABREU-TARDELLI, L. S. O chat educacional: O professor diante desse gênero emergente. In: Gêneros Textuais \& Ensino. DIONISIO, A. P. et al. (Org.). São Paulo: Parábola Editorial, 2010. p. 95-104.

, Elaboração de sequências didáticas: ensino e aprendizagem de gêneros em língua inglesa. In: DAMIANOVIC, M. C. (Org.). Material didático: elaboração e avaliação. Cabral: editora e livraria universitária. Taubaté, 2007

BAKHTIN, M; VOLOSHINOV, V. N. Marxismo e Filosofia da Linguagem. São Paulo: Editora Hucitec, 3ed, 1986.

BACHMAN, L. Fundamental considerations in language testing. Oxford: Oxford University Press, 1990.

BRASIL, SEF/MEC. Parâmetros Curriculares Nacionais- $3^{\mathbf{0}}$ e $4^{\mathbf{0}}$ ciclos do Ensino Fundamental- Língua Estrangeira. Brasília, DF: SEF/MEC, 1998.

BRASIL, SEF/MEC. Orientações Curriculares para o Ensino Médio: linguagens, códigos e suas tecnologias. Brasília, DF: SEB/MEC, 2006.

BRASIL. Ministério da Educação e do Desporto. Conselho Nacional de Educação. Diretrizes curriculares de Língua Estrangeira moderna para a educação básica. Curitiba, PR: SEED, 2008.

BRONCKART, J. P. Atividade de linguagem, textos e discursos: por um interacionismo sócio-discursivo. Trad.: A. R. Machado. São Paulo: EDUC, 1999.

CRISTOVÃO, V. L. L. Modelo didático de gênero como instrumento para formação de professores. In: MEURER, J. L.; MOTA-ROTH, D. (Org.) Gêneros Textuais. Bauru, SP: EDUSC, 2002.

. Sequências Didáticas para o ensino de línguas. In: DIAS, R; CRISTOVÃO, V. L. L. (Org.) O livro didático de Língua Estrangeira: múltiplas perspectivas. $1^{\text {a }}$ Ed. Campinas: Mercado de Letras, 2009. p. 305 - 344.

et al. Uma proposta de planejamento de ensino de língua inglesa em torno dos gêneros textuais. Revista Letras, Santa Maria, v. 20, n. 40, p. 191 - 215, jan./jun. 2010.

DESIRÉE MOTTA-ROTH et al (org). Análise de textos e de discursos: Relações entre teorias e práticas. Para ligar teoria à prática: Roteiro de perguntas para orientar a leitura/análise crítica de gênero. Santa Maria: PPGL- Editores, 2008, p. 243-272.

DOLZ, J. \& SCHNEUWLY, B. Pour un enseignement de l'oral. Initiation aux genres formels à l'école. Paris, ESF éditeur, 1998. 
- "Gêneros e progressão em expressão oral e escrita - elementos para reflexões sobre uma experiência suíça (francófona)". In: SCHNEUWLY, B. \& DOLZ, J. Gêneros orais e escritos na escola. Campinas, SP: Mercado de Letras, ([1996] 2004).

FIDALGO, S. S. A Avaliação do Ensino/Aprendizagem: ferramenta para a formação de agentes críticos. Dissertação de Mestrado. São Paulo: Pontífice Universidade Católica - PUC SP, 2002.

FREIRE, Paulo. Pedagogia do oprimido. Rio de Janeiro, Paz e Terra, 1970.

GIROUX, Henry. Os Professores como Intelectuais - Rumo a uma Pedagogia Crítica da Aprendizagem. Porto Alegre: Artmed, 1997.

LEFFA, V. O ensino de línguas estrangeiras no contexto nacional. Contexturas, APLIESP, n. 4, 1999. p. 13-24.

LÜDKE, M. e ANDRÉ, M. E. D. A. Pesquisas em Educação: abordagens qualitativas. São Paulo: EPU, 1996.

LUCKESI, C. C. Avaliação da aprendizagem escolar. São Paulo: Cortez, 1995.

MACEDO, L. Situação-Problema: forma e recurso de avaliação, desenvolvimento de competências e aprendizagem escolar. In: Perrenoud, P. et al. As competências para ensinar no século XXI: a formação dos professores e o desafio da avaliação. Porto Alegre: Artmed, 2002. p. 113-135.

MACHADO, A. R. e colaboradores. Linguagem e educação: $O$ ensino e a aprendizagem de gêneros textuais. Campinas, SP: Mercado de Letras, 2009.

. A perspectiva interacionista sociodiscursiva de Bronckart. In: MEURER, J. L.; BONINI, A.; MOTA-ROTH, D. (Orgs.) Gêneros: teorias, métodos e debates. São Paulo: Parábola Editorial, 2005, p. 237 - 259.

MARCUSCHI, L. A. Gêneros Textuais no Ensino de Língua. In: Produção textual, análise de gêneros e compreensão. São Paulo: Parábola Editorial, 2008, p. 146-225.

MEIRIEU, P. Aprender... Sim, mas como? Porto Alegre: Artmed, 1998.

MENDONÇA, M. R. de S. Um gênero quadro a quadro: história em quadrinhos. In: Gêneros Textuais \& Ensino. DIONISIO, A.P. et al. (Org.). São Paulo: Parábola Editorial, 2010. p. 209-224.

MENEZES, V. História do Material didático de língua inglesa no Brasil. In DIAS, R.; CRISTÓVÃO, V. L. L. O livro didático de língua estrangeira: múltiplas perspectivas. Campinas: Mercado de Letras, 2009. p. 17-56.

MEURER, J. L. et al (Org.). Gêneros: teorias, métodos e debates. São Paulo: Parábola Editorial, 2005. 
PERRENOUD, P. Dez novas competências para ensinar. Porto Alegre: Artmed, 2000.

RAMOS, P. C. A avaliação desmistificada. São Paulo: Artmed, 2001.

RODRIGUES, L. D. Gêneros textuais acadêmicos e ensino da língua inglesa: um caminho para a motivação e a autonomia. 2008. $174 \mathrm{f}$. Dissertação (Mestrado) Universidade Federal do Pará, Instituto de Letras e Comunicação. Belém, 2008. Curso de Mestrado em Letras.

ROMÃO, J. E. Avaliação Dialógica: desafios e perspectivas. São Paulo: Cortez \& Instituto Paulo Freire, 1998. 136p.

SAVIANI, D. A pedagogia histórico-crítica: primeiras aproximações. 9 ed. Campinas:

Autores Associados, 2005.

SZUNDY, P. T. C.; CRISTOVÃO, V. L. L. Projetos de formação pré-serviço do professor de língua inglesa: sequências didáticas como instrumentos no ensinoaprendizagem. RBLA. v. 8, n. 1, p. 115-137, 2008. 


\section{ANEXO}

Nome:

Língua Estrangeira:

Abaixo, você tem algumas situações-problemas. Você precisa lê-las e respondê-las. Todas requerem opinião pessoal sobre as situações, portanto, fuja do senso comum e reflita a partir de seus conhecimentos teóricos e suas experiências em sala de aula.

1) Você está estudando para ser professor. É o seu primeiro dia de estágio e você dará sua primeira aula numa escola pública da cidade. Seu professor orientador pede para que você faça um plano de aula. Que abordagem você, como aluno-professor, escolheria e por quê?

2) Pense num conteúdo que você, como aluno-professor, deve ensinar os seus alunos na aula de LE (Língua Estrangeira). Como você abordaria esse conteúdo por meio da abordagem escolhida anteriormente?

3) É fato que a tecnologia está cada vez mais interligada ao ser humano e, por isso, seu professor orientador de estágio pede que você trabalhe com chat (MSN, skype, entre outros meios virtuais de comunicação) em sala de aula. $\mathrm{O}$ que você pensaria disso e como se daria essa abordagem?

4) Tendo em conta que o jovem brasileiro não tem o hábito da leitura e demonstra interesse por ler Histórias em Quadrinhos, como você sugeriria algumas atividades pedagógicas em torno das HQs?

5) Sabe-se que a avaliação praticada pelas escolas, hoje, é mensurada pelo sistema de notas, o que, muitas vezes, não faz parte de um processo. Para que a avaliação da aprendizagem tenha implicações de produção de conhecimento e efeito de sentido sobre o aluno, imagine uma situação em que você deva elaborar uma avaliação pautada em gêneros. Como se daria essa elaboração e a partir da abordagem defendida anteriormente? Justifique a sua escolha. 